\title{
A Case of Post-traumatic Syringomyelia. Neuropathological Findings after 1 Year of Cystic Drainage
}

\author{
D. Foo, MD, ${ }^{1,3}$ A. Bignami, $M D,{ }^{2,4}$ A. B. Rossier, MD \\ ${ }^{1}$ Spinal Cord Injury and ${ }^{2}$ Spinal Cord Research Laboratory Services, West Rox- \\ bury Veterans Administration Medical Center, and the Departments of ${ }^{3}$ Neurology \\ and ${ }^{4}$ Neuropathology, Harvard Medical School, Boston, Massachusetts, USA.
}

\section{Summary}

A 58-year-old man sustained C4-C5 post-traumatic myelopathy with C3-C4 subluxation, slight compression of $C 3$ vertebral body, C4 spinous process fracture and C6 compression fracture. He subsequently developed syringomyelia from C4 to C6, which was shunted into the subarachnoid space. Postoperatively, there was some but insignificant improvement of his symptoms although a postoperative metrizamide spinal computerised tomography showed compelte drainage of the cyst. This patient died 1 year later. Autopsy examination of the spinal cord showed extensive damage of the posterior half of the cord at C3-C4 but the damage was much less extensive from $C 4$ to $C 6$ (where the syrinx was located), affecting mainly the right dorsal column at $\mathrm{C} 4$ and the right dorsal column and right anterior horn at C5-C6.

In this patient, the syrinx developed in the partially damaged segments of the cord at the level of the spinal fractures and complete drainage of the cyst was not followed by satisfactory relief of his symptoms.

Key words: Post-traumatic syringomyelia; Autopsy; Shunt; Pathogenesis.

Post-traumatic syringomyelia is a well known complication of spinal cord injury but there have been few autopsy studies of these patients (Barnett et al., 1973; Horenstein, 1970; Jensen \& Reske-Nielsen, 1977; Klawans, 1968; Oakley et al., 1981; Vernon et al., 1982; Vernon et al., 1983). Here we report a case of posttraumatic syringomyelia with neuropathological findings 1 year after cystic drainage. The purpose of this paper is to show that a syrinx developed in the 
damaged segments of the cord at the site of the spinal injury and complete drainage of the cyst may not necessarily result in the satisfactory relief of symptoms.

\section{Case report}

This 58-year-old man became paralysed with no motion in the extremities in November 1977 after his car was hit from behind by another vehicle. A few hours later, he regained some movement of his legs. Cervical radiographs revealed the presence of spondylotic changes, $\mathrm{C} 3-\mathrm{C} 4$ retrolisthesis, slight compression of $\mathrm{C} 3$ body, fracture of the $\mathrm{C} 4$ spinous process and compression fracture of C6. The fractures were immobilised with skull traction and the patient was transferred to our care 3 weeks after the injury. Neurological examination on admission showed normal mental and cranial nerve functions with no Horner's syndrome. Hypalgesia was present in the dermatomes of C5 and C6 and analgesia below C6 bilaterally. Touch sensation was densely impaired below C4 bilaterally. Vibration sense was diminished in the upper limbs but absent in the legs, and position sense was not detectable in the hands and lower extremities. All the limb muscles were densely paretic and spastic, especially in the upper limbs. The biceps, brachioradialis and ankle reflexes were absent and the triceps and knee jerks were hypoactive with bilateral Babinski signs. The patient had weak voluntary control of the anal sphincter and the bulbocavernosus response was positive.

Skull traction was discontinued 1 month after the injury. When the patient was discharged in April 1979, pain sensation was diminished below C7 on the right and C6 on the left side and touch was decreased below $\mathrm{C} 4$ bilaterally; vibration and position senses were normal in the shoulders, impaired in the elbows and hands but absent in the legs. He had more motor than sensory return and was able to ambulate with a walker without any orthosis.

In February 1981, the patient noticed pain and increased numbness and stiffness in the trunk and extremities. There was no associated lesion in the bowel, bladder or skin to account for the increased spasticity. At the same time, he had increased difficulty with his daily activities and lost his ability to walk. When he was examined in March 1982, the legs were very spastic and the sensations of pain and touch were impaired below C3 bilaterally with no change of proprioception, or of motor power. Gas myelography revealed enlargement of the cord at C4, C5 and C6 vertebral segments and there was partial collapse of these segments when the patient was changed from the head-flat to the 5-degree head-down position. Metrizamide spinal computerised tomography (CT) was not satisfactory because of poor resolution of the images and because of metallic artefacts from the patient's dental fillings at the $\mathrm{C} 3$ and $\mathrm{C} 4$ segments.

The patient was operated in May 1982. Laminectomy of C4 and C5 was performed, followed by incision of the dural, arachnoid and pial membranes. A $6 \mathrm{~mm}$ long midline myelotomy was made at the $\mathrm{C} 5$ cord level and a cavity about $2 \mathrm{~cm}$ long was found within the spinal cord. The cavity was shunted to the subarachnoid space with a silastic $\mathrm{K}$ tube (Rossier et al., 1985). The intramedullary limb extended 1 centimetre cranially and 1 centimetre caudally from the site of insertion of the shunt and the extramedullary limb, about $2 \mathrm{~cm}$ long, was directed caudally in the subarachnoid space. The dura was closed, followed by closure of the surgical wound in multiple layers. Postoperatively, there was minor improvement of the pain but there was no change in the sensory deficits or in spasticity. Spinal CT 2 months after the operation showed no accumulation of the dye inside the cord within 30 minutes post-metrizamide and a small cervical cord (Fig. 1). The patient expired in September 1983 from carcinoma of the colon.

At autopsy, the entire spinal cord was removed with the spine, and was examined after prolonged fixation in formalin. The remaining laminae were removed and the spinal cord was dissected out with the dura. After the dura was opened, the shunt was found to be attached to the spinal cord at the $\mathrm{C} 5$ root level with no arachnoid adhesions. Above the site of insertion of the shunt and between the $\mathrm{C} 3$ and $\mathrm{C} 4$ roots, the cord was markedly 


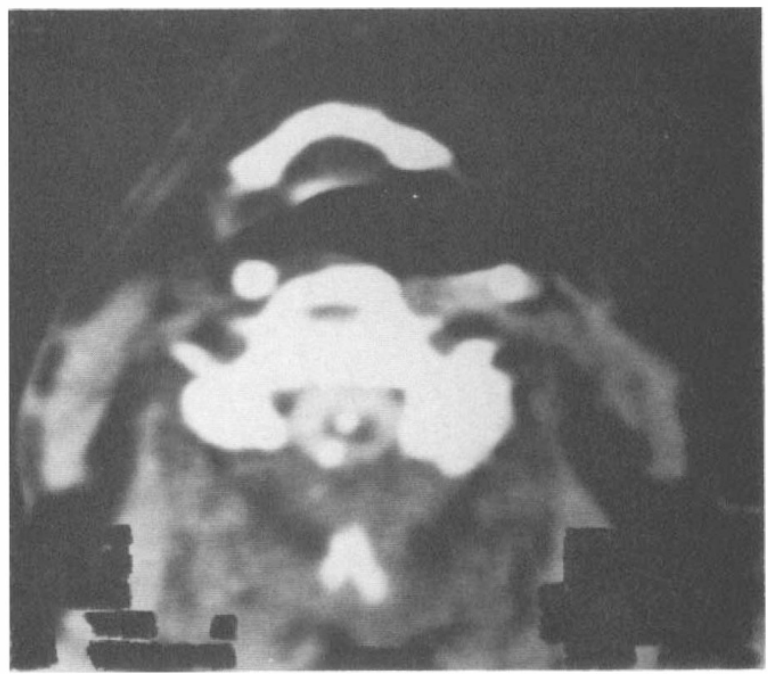

Figure 1 Spinal CT within 30 minutes after intrathecal injection of metrizamide showing a small cord at C5 with no evidence of accumulation of the dye inside the cord. The extramedullary arm of the shunt ( $\mathrm{K}$ tube) was seen in the subarachnoid space.

constricted. Radio-opaque fluid was injected into the shunt and radiographs of the cervical cord were taken. The shunt was patent and no residual cavity was found within the cord. The intramedullary arm of the $\mathrm{K}$ tube extended cranially to the middle part of $\mathrm{C} 4$ and caudally to the middle part of C6.

The shunt was removed and the spinal cord was cut in transverse sections. Gross examination of the cord at the level between $\mathrm{C} 3$ and $\mathrm{C} 4$ showed extensive damage with some preservation of normal tissue anteriorly. A cavity was present in the central part of the cord from $\mathrm{C} 4$ to $\mathrm{C} 6$. Above $\mathrm{C} 3$, there was greyish discoloration of the dorsal columns and below $\mathrm{C} 6$, greyish discoloration of the lateral columns, indicating ascending and descending Wallerian degeneration, respectively.

Histological examination of the spinal cord at $\mathrm{C} 4$ showed a cavity in the ventral part of the right dorsal column; loss of neurons and axons and gliosis were present in the right dorsal column and in the tissue surrounding the syrinx, including the anterior white commissure (Fig. 2). At C5-C6, the cavity was located in the central part of the cord, involving the ventral part of both dorsal columns, the anterior white commissure and part of the left anterior column (Fig. 3); a very small cyst was noted in the right anterior horn and there was necrosis of the tissue in the right dorsal column and anterior horn. Reaction to the shunt was limited to a few giant cells in the wall of the syringomyelia. Examination of the spinal cord between $\mathrm{C} 3$ and $\mathrm{C} 4$ showed severe damage to the posterior half of the spinal cord extending to both anterior horns (Fig. 4); the damaged tissue showed extensive gliosis. There was almost complete Wallerian degeneration of the posterior columns at $\mathrm{C} 2$ with only a few myelinated axons preserved at the periphery of the spinal cord. There was no evidence of the presence of other cysts in the rest of the cord above $\mathrm{C} 4$ and below $\mathrm{C} 6$.

\section{Discussion}

In our patient, involvement of the anterior white commissure by the syrinx at C5 and C6 (Fig. 3) accounted for the impairment of pain sensation at this level. At C4 (Fig. 2), the cyst was located in the ventral part of the right dorsal 


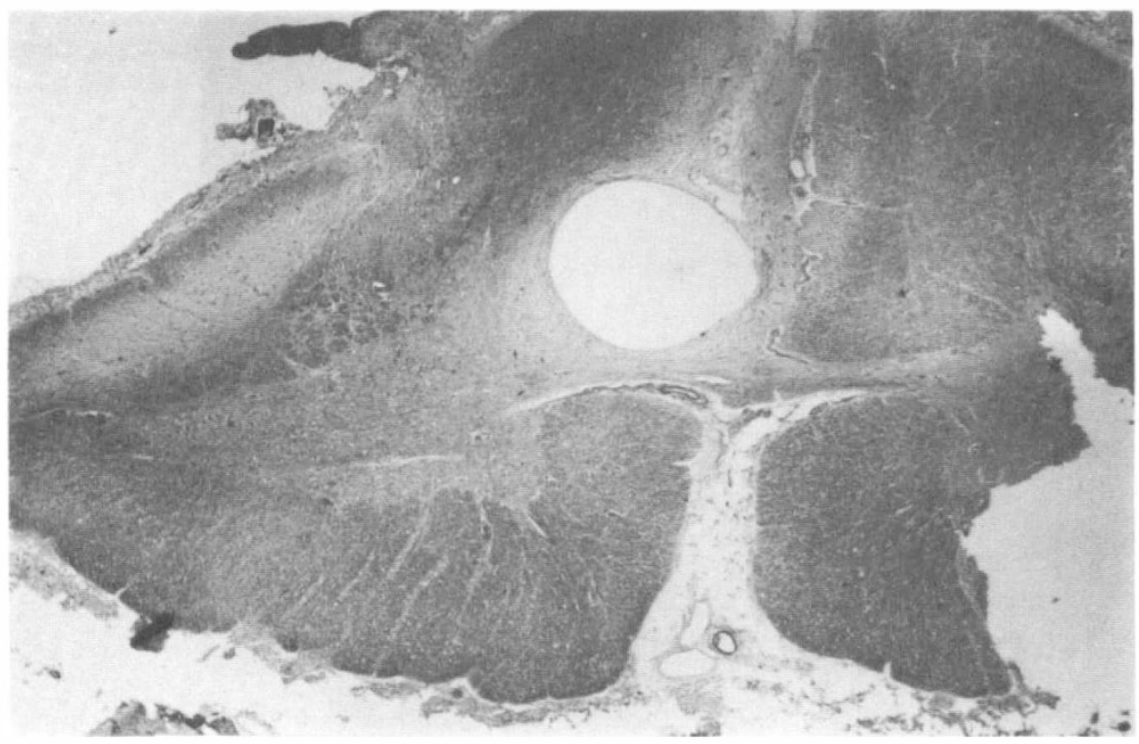

Figure 2 Low-power view of the spinal cord at C4 showing a cavity in the ventral part of the right dorsal column and necrosis of the tissue surrounding the syrinx, including the anterior white commissure. There was also necrosis of the tissue in the medial portion of the right dorsal column (Luxol-fast stain times 7).

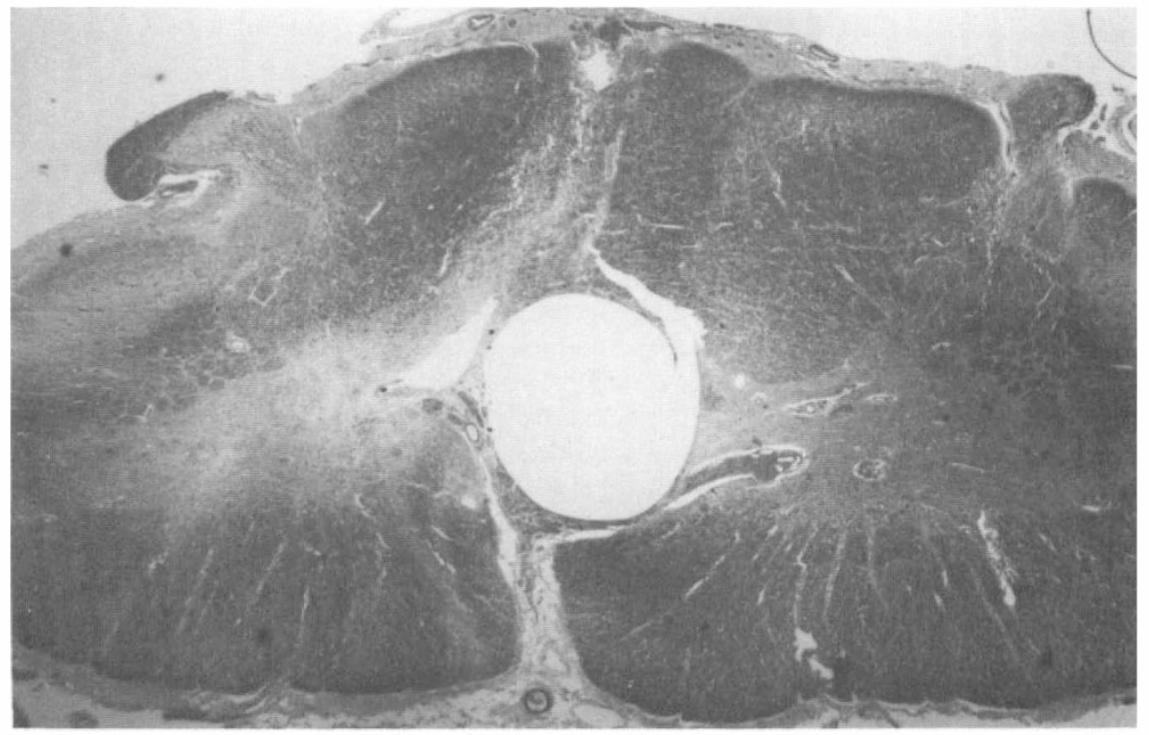

Figure 3 Low-power view of the spinal cord at C5-C6 showing a central cavity involving the ventral part of both dorsal columns, the anterior white commissure and part of the left anterior column. A very small cyst was present in the right anterior horn and there was necrosis of the tissue in the right dorsal column and right anterior horn (Luxol-fast stain times 7). 


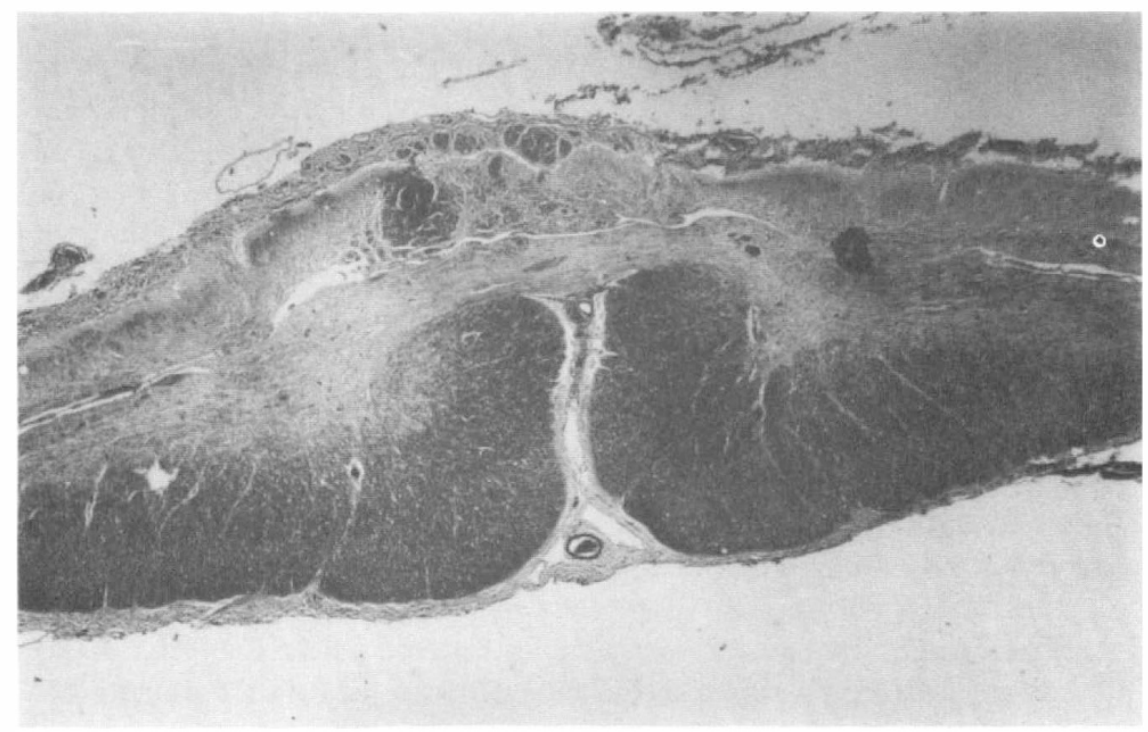

Figure 4 Low-power view of the spinal cord at C3-C4 showing severe damage to the posterior half of the cord, extending to involve the anterior horn bilaterally (Luxol-fast stain times 7).

column and the cause of the partial loss of pain sensation at this level was probably the result of degeneration of the anterior white commissure ventral to the cyst. However, it is difficult to account for the increased spasticity; it is unclear and doubtful that involvement of parts of the dorsal and anterior columns could have been the cause of this symptom.

Holmes (1915) presented pathological material showing a central area of degeneration within the spinal cord at sites adjacent to gun shot wounds extending up and down over several segments. Wozniewicz et al. (1983) studied the gross anatomy and histological appearance of the spinal cord in 120 patients who died as a result of spinal injury and described three types of lesions: (1) total disorganisation of the cord at the site of trauma; (2) total disorganisation of the cord at the site of trauma associated with pipelike necrosis extending up and down from the main injury, similar to the observation of Holmes (1915); and (3) partial spinal cord necrosis localised to the area of supply of intraspinal arteries. Holmes (1915) postulated that a syrinx resulted from pressures within the foci of degeneration. Jensen and Reske-Nielsen (1977) believed that their cases lent support to Holmes' theory, in that their pathological findings suggested elevated intraparenchymal pressure without signs of haemorrhage or vascular compromise. In our patient, the syrinx extended from $\mathrm{C} 4$ to $\mathrm{C} 6$, within the area of the partially damaged segments of the cord with no evidence of degeneration or necrosis of cord tissues above and/or below the level of the spinal fractures. It has been recognised that severe local trauma inflicted on the spinal cord may result in a local cystic lesion replacing the necrotic and haemorrhagic tissue (Barnett et al., 1973) but autopsy confirmation of these cases is rare. Freeman and Wright (1953) in several instances of experimental spinal cord injury in dogs kept alive for many weeks and months, demonstrated a cystic lesion at the 
trauma site. Bastian (1867), in an autopsy of a 26-year-old man with posttraumatic tetraplegia, revealed 'a large rupture extending obliquely from before, backwards across the grey matter of the right side of the upper cervical cord'. In another patient described by Lougheed and Geisler (Barnett et al., 1973), a central syrinx was found at T5 at operation; this patient sustained T7 complete paraplegia associated with fracture and disclocation of T6 and T7 about 1 year before the operation. Wozniewicz et al. (1983) observed a cyst, a few millimetres in diameter and filled with translucent material, in the region of the posterior horn of a patient who had partial traumatic necrosis of the spinal cord. Although it is possible that more than one mechanism is involved in the pathogenesis of post-traumatic cystic and non-cystic progressive myelopathy (Stevens et al., 1985), our case supports the hyposthesis that post-traumatic syringomyelia is the result of cystic degeneration of the damaged cord tissue at or near the site of the original spinal injury (Rossier et al., 1985).

The indications for surgical treatment in our patients with post-traumatic syrinx were progressive muscle weakness and severe pain (Rossier et al., 1985), and it has been demonstrated that in general, pain and motor deficits but not sensory or reflex deficits showed consistently good response to operative treatment (Rossier et al., 1985; Shannon et al., 1981; Tator et al., 1982). Shunt failure, however, could occur, leading to the delayed onset of neurological deterioration. In our patient, both the post-operative spinal CT and autopsy study of the shunt showed it was patent and the syrinx was completely drained. However, he only showed some but insignificant improvement of pain without improvement of the sensory level and spasticity; degeneration of the cervical cord tissue was probably permanent and could not be reversed by the shunting operation.

\section{References}

BASTIAN HC 1867 On a case of concussion-lesion with extensive secondary degeneration of the spinal cord. Proceedings of the Royal Medical and Chirurgical Society of London. 50:499.

BARNETT HJM, Jousse AT, BALl MJ 1973 Pathology and pathogenesis of progressive cystic myelopathy as a late sequel to spinal cord injury. BARNETT HJM, FosTER JB, HUdGSON P (eds) Syringomyelia. WB Saunders, London, pp. 179-219.

FREEMAN LW, WRIGHT TW 1953 Experimental observations of concussion and contusion of the spinal cord. Annals of Surgery 137:433-443.

Holmes G 1915 The Goulstonian lectures on spinal injuries of warfare. British Medical fournal 2:769-774.

HORENSTEIN S 1970 Intramedullary cyst formation with progressive gliosis (traumatic syringomyelia) following spinal cord injury. Transactions of the American Neurological Association 95:263-266.

JENSEN F, RESKE-NIELSEN E 1977 Post-traumatic syringomyelia. Review of the literature and two new autopsy cases. Scandinavian fournal of Rehabilitation Medicine 9:35-43.

KLAWANS HL 1968 Delayed traumatic syringomyelia. Diseases of the Nervous System 29:525-528.

OAKLEY JC, OJeman GA, Alvord EC Jr 1981 Post-traumatic syringomyelia. Case report. fournal of Neurosurgery 15:276-281.

Rossier AB, Foo D, Shillito J, Dyro FM 1985 Post-traumatic cervical syringomyelia: incidence, clinical presentation, electrophysiological studies, syrinx protein and results of conservative and operative treatment. Brain 108:439-461.

Shannon N, Symon L, Logue V, Cull D, Kang J, Kendall BE 1981 Clinical features, investigation and treatment of post-traumatic syringomyelia. Fournal of Neurology, Neurosurgery and Psychiatry 44:35-42. 
Stevens JM, Olney JS, Kendall BE 1985 Post-traumatic cystic and non-cystic myelopathy. Neuroradiology 27:48-56.

TATOR CH, MEgURo K, Rowed DW 1982 Favorable results with syringosubarachnoid shunts for treatment of syringomyelia. Fournal of Neurosurgery 56:517-523.

Vernon JD, Silver JR, OHRY A 1982 Post-traumatic syringomyelia. Paraplegia 20:339-364.

VERNON JD, SILVER JR, SYMON L 1983 Post-traumatic syringomyelia: the results of surgery. Paraplegia 21:37-46.

WozNiewicz B, Filipowicz K, Swiderska SK, Deraka K 1983 Patho-physiological mechanism of traumatic cavitation of the spinal cord. Paraplegia 21:312-317. 